\title{
Increase the Efficiency of a Gas Turbine Unit for Gas Turbine Locomotives by Means of Steam Injection into the Flow Section
}

\author{
Evgeny Filinov, Andrey Tkachenko, Hewa Hussein Omar and Viktor Rybakov \\ Samara National Research University, Department of Aircraft Engine Theory, Samara, Russian Federation
}

\begin{abstract}
In the modern world of railways, electrification is given great importance. Currently, more than $50 \%$ of all freight traffic carried out by electric traction. However, today, about half of the railways are not electrified, so it is necessary to use thermal engines to drive the locomotive. One of the possible variant is use gas turbine unit. The power of the gas turbine unit is given to the electric generator, and the electric motors drive the locomotive. In the present paper, as a power plant of a gas turbine locomotive, considered gas turbine unit with a twin -shaft gas generator of two schemes: 1- with steam supply to the inlet of the high-pressure turbine (into the combustion chamber) and 2- with steam supply to inlet of the free turbine. By CAE system of ASTRA, Collaboration operation lines calculated for different variants of steam injection. When the steam injected into the inlet of a free turbine and a highpressure turbine. in the case of steam supply to the input of the free turbine and the high-pressure turbine there is a significant shift in Collaboration operation lines, which can lead to a decrease in the gas-dynamical stability of the compressors, and efficiency. To maintain the position of Collaboration operation lines, was applied the correction of the throughput capacity of free turbine nozzle vanes (by 15\%). In the case of steam supply to the inlet of a free turbine, to ensure gas-dynamic stability of the compressors, a change in the throughput capacity of its nozzle vanes is required.
\end{abstract}

\section{Introduction}

In the modern world of railways, electrification is given great importance. In Switzerland, almost $100 \%$ of railways (about 3,000 km) are electrified, in Sweden over $60 \%$ (more than $7,500 \mathrm{~km}$ ), in Italy - about $50 \%$ (over $8,000 \mathrm{~km}$ ). Currently, more than $50 \%$ of all freight traffic carried out by electric traction [1].

Railway electrification increases throughput and carrying capacity, operation reliability, reduces operating costs, allows to make rail transport more comfortable. In addition, electrified railways are more environmental friendly. However, today, about half of the railways are not electrified, so it is necessary to use thermal engines to drive the locomotive. One of the possible variant is use gas turbine unit. The power of the gas turbine unit is given to the electric generator, and the electric motors drive the locomotive. In the USSR, work on the creation of a gas turbine locomotive began in 1954. Several models of locomotives were developed and produced prototypes that passed the test. In the 1970 s, projects to create gas turbines discontinued, since they could not be in competition with electric locomotives and diesel locomotives.
One of the known methods to increase the efficiency of gas turbines is steam injection into the flow part [2-4]. Also, steam injection reduces the level of polluting emissions of NOx and $\mathrm{CO}$ oxides into the atmosphere [5-7].

\section{Problem description}

In the present paper, as a power plant of a gas turbine locomotive, considered gas turbine unit (GTU) with a twin -shaft gas generator of two schemes: 1- with steam supply to the inlet of the high-pressure turbine (into the combustion chamber) and 2- with steam supply to inlet of the free turbine. Calculation scheme of the plant is shown in figure 1.

\section{Calculations}

By CAE system of ASTRA [8, 9], Collaboration operation lines calculated for different variants of steam injection. Position of Collaboration operation lines on compressors map when the steam injected into the inlet of a free turbine and a high-pressure turbine shown in Figures 2 and 3. 


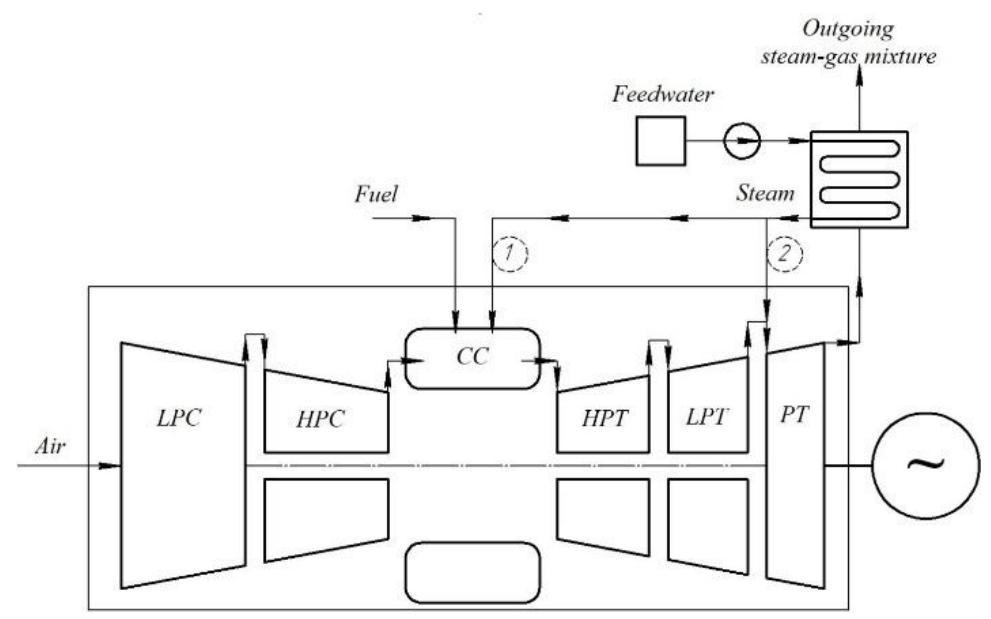

Figure 1. Calculation scheme of complex cycle gas turbine unit with a twin -shaft gas generator (1- Steam supply to the input of highpressure turbine; 2- Steam supply to the inlet of a free turbine).

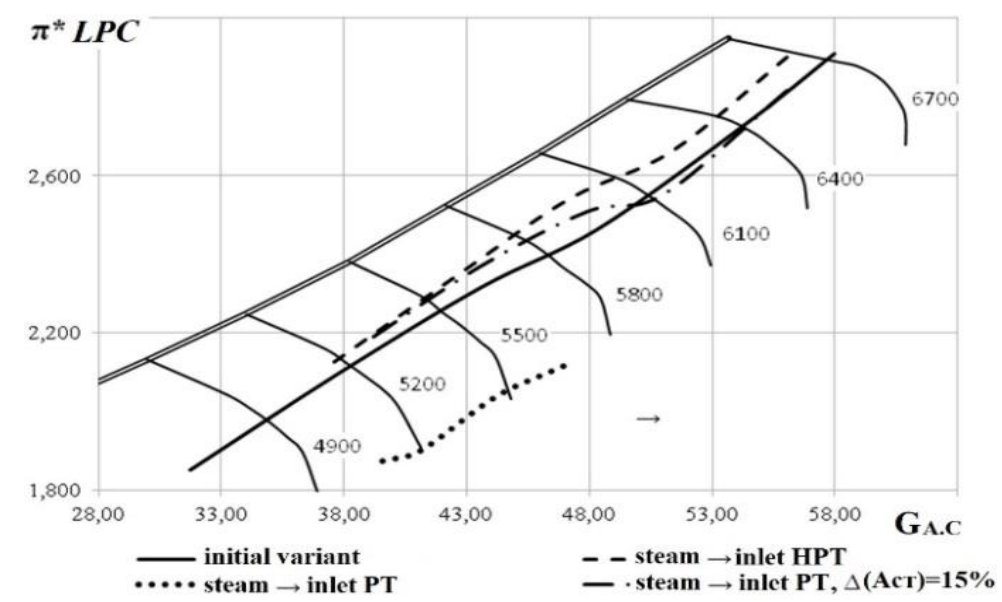

Figure 2. Collaboration operation lines on low-pressure compressor map.

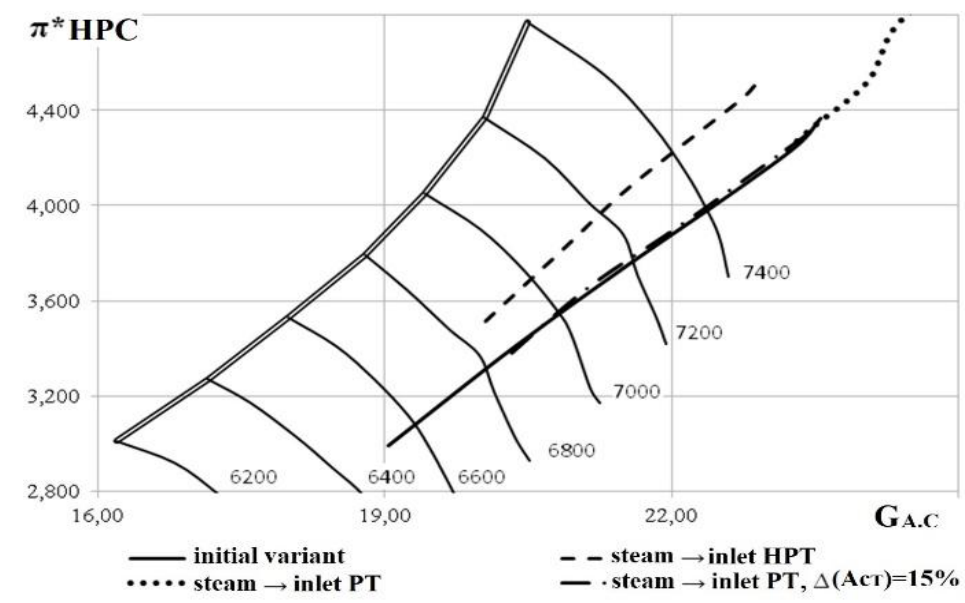

Figure 3. Collaboration operation lines on of high-pressure compressor map.

As can be seen from the presented results, in the case of steam supply to the input of the free turbine and the high-pressure turbine there is a significant shift in Collaboration operation lines, which can lead to a decrease in the gas-dynamical stability of the compressors, and efficiency. To maintain the position of Collaboration operation lines, was applied the correction of the throughput capacity of free turbine nozzle vanes (by 15\%). The resulting Collaboration operation lines for this variant also shown in figures 2 and 3. In this case, the position of the Collaboration operation lines practically coincides with the initial version of the gas turbine without heat recovery of exhaust gases.

Figures 4-7 shows the calculating results of three variants of gas turbine plant: The initial version, with steam supply to the inlet of the high-pressure turbine and with steam supply to the inlet of the free turbine, with the correction of the capacity of its nozzle vanes. 


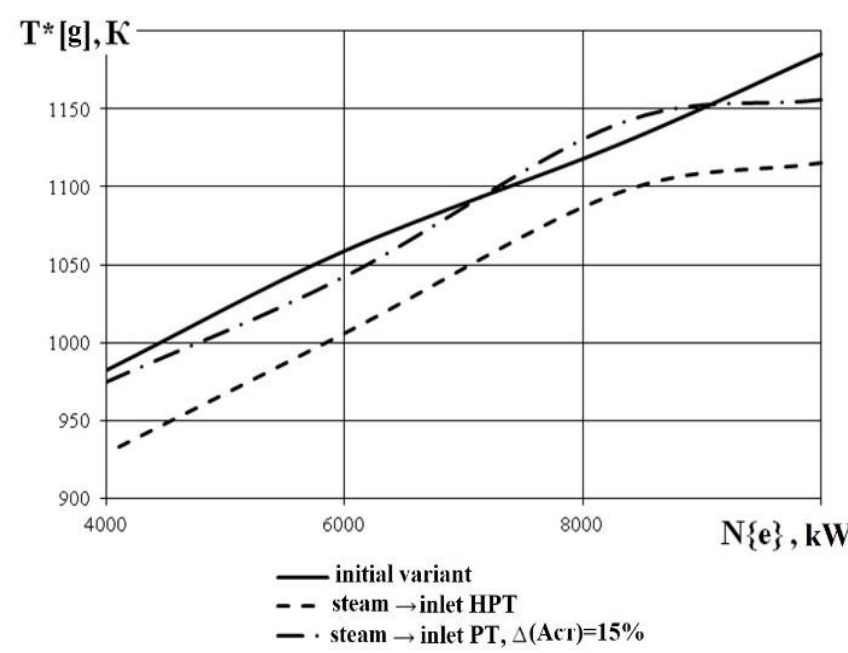

Figure 4. Relationship of the gas temperature in front of the high-pressure turbine at the operation mode of the gas turbine plant with a two-shaft gas generator.

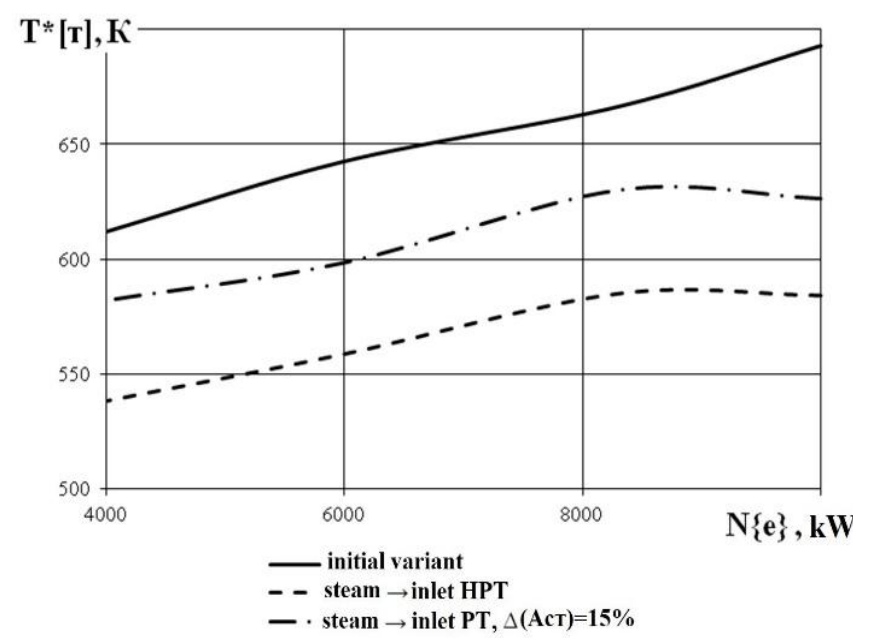

Figure 5. Relationship of the gas temperature after free-power turbine from the operation mode of the gas turbine plant with a two-shaft gas generator.

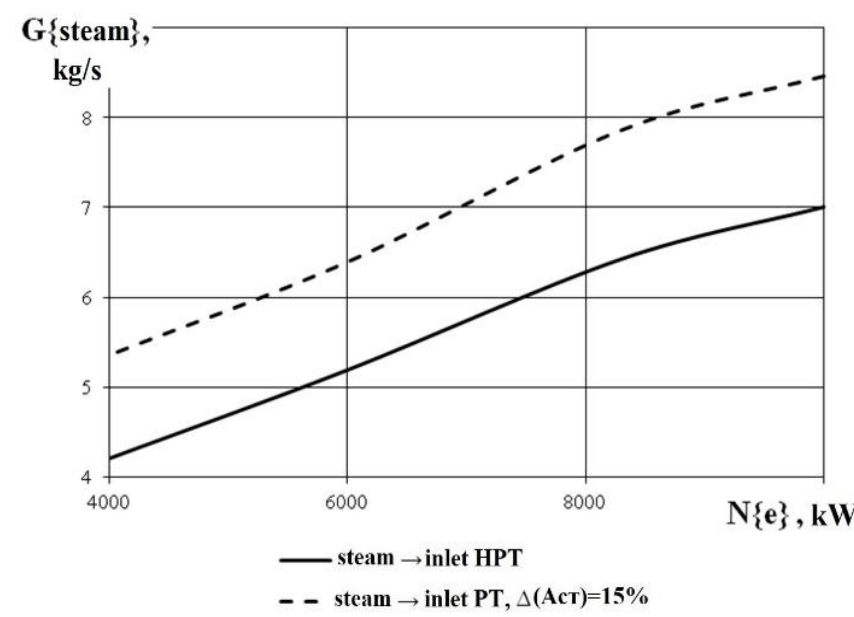

Figure 6. Relationship of the steam flow entering the flow path part from the operation mode of the gas turbine plant with a two-shaft gas generator.

As can be seen from the presented results, in the case of steam supply to the inlet of a free turbine, to ensure gas-dynamic stability of the compressors, a change in the throughput capacity of its nozzle vanes is required, while the increase in effective efficiency is about $1.5 \%$ when steam flow rate at $8.5 \mathrm{~kg} / \mathrm{s}$. And steam supply to the inlet of the high pressure turbine allows to increase efficiency about $5 \%$ when steam flow rate at $7 \mathrm{~kg} / \mathrm{s}$.

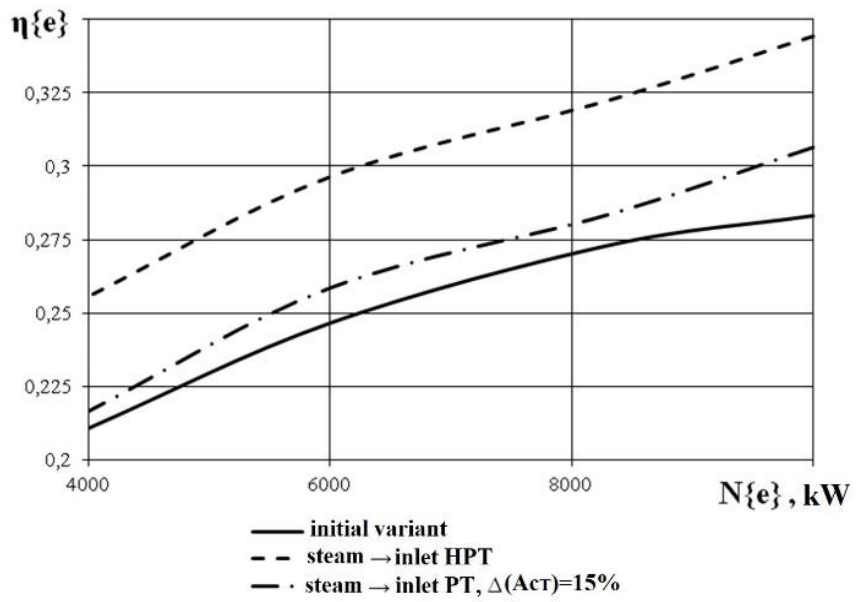

Figure 7. Relationship of effective efficiency from the operation mode of the gas turbine plant with a two-shaft gas generator.

It is known that the steam injection into the flow part of engine affects on the emission of harmful substances. Due to the tests carried out in the SSAU on combustion chamber compartments of two NK engines, the results which in the form of relative values of the emission index of nitric oxide $E \bar{J}_{\mathrm{NO}_{\mathrm{x}}}$ are shown in figure 8, we estimate the reduction of nitrogen oxides $\mathrm{NO}_{\mathrm{x}}$ at different ways of supplying injected component.

$$
\mathrm{E} \overline{\mathrm{NO}}_{\mathrm{NO}_{\mathrm{x}}}=\frac{\mathrm{E}_{\mathrm{NO}_{\mathrm{x}} \text { with water }}}{\mathrm{E}_{\mathrm{NO}_{\mathrm{x}} \text { with out water }}}
$$

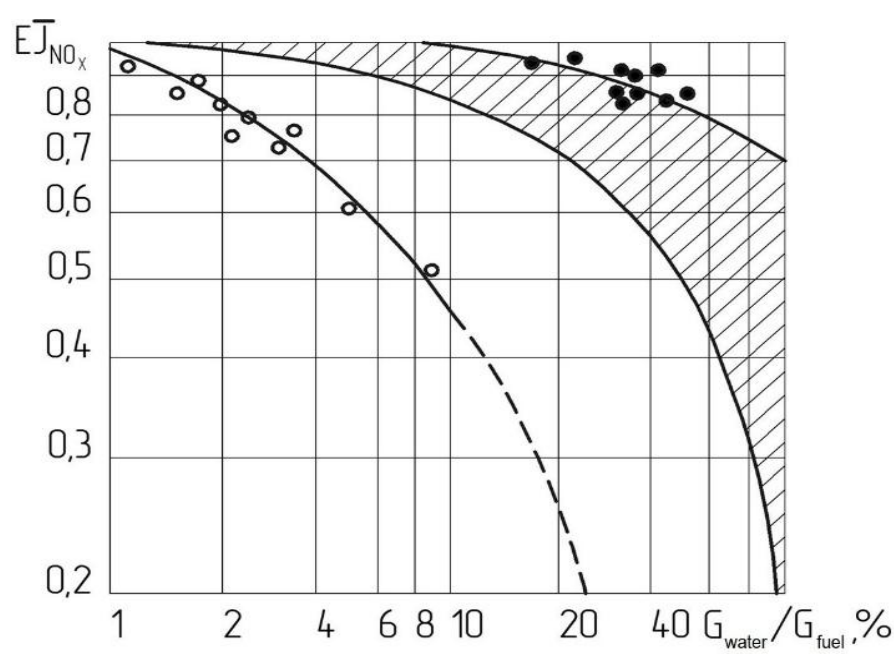

Figure 8. Relationship of effective efficiency from the operation mode of the gas turbine plant with a two-shaft gas generator.

In figure 8: ॰, - - attempts of Professor J. A. Knish on compartments of combustion chamber: $\circ$ emulsion injection [8]; - - proximate water injection; //// Literature data for water injection. 
In Table 1 shows the data of reduction of nitrogen oxide emission $\mathrm{NO}_{\mathrm{x}}$ depending on amount of supplied water.

Table 1. Data of reduction of nitrogen oxide emission $\mathrm{NO}_{\mathrm{x}}$ depending on amount of supplied water.

\begin{tabular}{|l|l|l|}
\hline $\begin{array}{l}\text { Relative } \\
\text { water flow } \\
\text { rate } \boldsymbol{g}\end{array}$ & $\begin{array}{l}\text { Ratio of water } \\
\text { flow rate to fuel } \\
\text { flow rate } \\
\boldsymbol{G}_{\mathbf{w}} / \boldsymbol{G}_{\boldsymbol{f}}, \boldsymbol{\%}\end{array}$ & $\begin{array}{l}\text { Nitrogen oxide } \\
\text { emission index } \mathbf{E} \overline{\mathbf{J}}_{\mathbf{N O}_{\mathbf{x}}} \\
\text { (Literature data } \\
\text { (figure 8)) }\end{array}$ \\
\hline 0,01 & 36 & $0,59-0,86$ \\
\hline 0,02 & 70 & $0,37-0,76$ \\
\hline 0,03 & 102 & $0,2-0,7$ \\
\hline
\end{tabular}

\section{Conclusion}

According to the data given, with a relative water flow rate of $\mathrm{g}=0.01$, the emission of nitrogen oxides decreases by $14 \%$ at least, and at $g=0.03$ - by $30 \%$. As can be seen from the graph shown in Figure 8, a stronger reduction in nitrogen oxides can be achieved by supplying a fuel-water emulsion instead of separately injecting of components. In the same way, it is possible to reduce water flow rate by saving the initial emission level of nitrogen oxides.

Thus, most expedient way to increase the efficiency of a gas turbine plant with a two-shaft gas generator is heat utilization of exhaust gas with steam supply to the inlet high-pressure turbine (the growth of effective efficiency is about $5 \%$ when a steam flow rate at $7 \mathrm{~kg} / \mathrm{s}$ ), while collaboration operation lines on compressors map is shifted slightly, and reserves of the stable operation of the compressors preserved. at acceptable level. In addition, the emission characteristics of the engine are improved $[9,10]$.

\section{Acknowledgment}

This work was supported by the Ministry of education and science of the Russian Federation in the framework of the implementation of the Program of increasing the competitiveness of Samara University among the world's leading scientific and educational centers for 2013-2020 years.

\section{References}

1. D. A. Ryzhkov, A. A. Shubin High technologies in instrument and mechanical industries and development of innovative activities in higher education: materials of Fserasiskoi scientifictechnical conference 4 92-95 (2013)

2. De M. Paepe, E. Dick Applied Thermal Engineering 21 (2) 135-15 (2001)

3. S.S. Stecco, U. Desideri, B. Facchini, N. Bettagli, ASME 1993 International Gas Turbine and Aeroengine Congress and Exposition 2 (1993)

4. K. Mathioudakis Journal of Engineering for Gas Turbines and Power 124 (3) 489-495 (2002)

5. E. Benini, S. Pandolfo, S. Zoppellari Applied Thermal Engineering 29 (17-18) 3506-3510 (2009)

6. L. Sun, Q. Zheng, Y. Li, M. Luo, R.K. Bhargava Journal of Engineering for Gas Turbines and Power 135 (1) (2013)

7. A. Maiboom, X. Tauzia Fuel 3179-3192 90 (11) (2011)

8. I.N. Krupenich, E.P. Filinov, Y.A. Ostapyuk, A.Yu. Tkachenko International Journal of Mechanical Engineering and Robotics Research 6 (1) 36-41 (2017)

9. V.S. Kuz'michev, A.Yu. Tkachenko, Ya.A. Ostapyuk, I.N. Krupenich, E.P. Filinov ICMSC 136-140 (2017)

10. V.S. Kuz'michev, A.Yu. Tkachenko, I.N. Krupenich, V.N. Rybakov, E.P. Filinov, Y.D. Novikova 53rd AIAA/SAE/ASEE Joint Propulsion Conference (2017)

11. A. B. Tsapkova, Y. A. Knysh, Y. I. Tsibizov Patent of the Russian Federation No. 128248 (2013) 